\title{
Analysis of predictive capabilities of metacognitive strategies in the expression of professional thinking of military personnel
}

\section{O. Smolentsev ${ }^{1}$, J. M. Perevozkina ${ }^{2}$, M. I. Fedorishin ${ }^{2,3}$}

\author{
${ }^{1}$ Saratov Military Order of Zhukov Red Banner Institute of the National Guard of the Russian \\ Federation \\ ${ }^{2}$ Novosibirsk State Pedagogical University \\ ${ }^{3}$ Novosibirsk Military Order of Zhukov Institute named after General of the Army \\ I. K. Yakovlev troops of the National Guard of the Russian Federation
}

DOI: 10.18255/1996-5648-2021-4-638-647

Research article

Full text in Russian

The article examines professional thinking in relation to the conditions of military activity. The goal is to identify a model of cadets' metacognitive competence, contributing to the successful formation of professional thinking in the conditions of military activity. The construction of two regression models is carried out by means of multiple stepwise regression analysis with inclusion. In the first model, the variable response was the oversituational style of thinking of servicemen, determined by the questionnaire "Determination of the dominant level of problematicity in solving service-professional problem situations.» In the second model of the variable, the response was the type of professional thinking determined on the basis of the case method. Cadets' metacognitive strategies were used as variable predictors. It was possible to establish that both regression models are statistically significant, the level of error probability is less than $0.01 \%$ and explain more than $40 \%$ of the variability of the variable responses. All metacognitive strategies (six variable predictors) in the first model have a statistically significant relationship with variable responses $(p \leqslant 0.05)$. The predictive influence on the dominance of a certain type of professional thinking among cadets has the character of structural interaction. Metacognitive strategies such as information acquisition, concentration, time management and the level of reflection are facilitators for the formation of a supra-situational level of cadets' professional thinking. Whereas metacognitive knowledge and metacognitive activity act as inhibitors.

Keywords: professional thinking; metacognitive strategies; over-situational thinking; structure; interdetermination; military personnel; cadets

\section{INFORMATION ABOUT AUTHORS}

Smolentsev, I. O. | E-mail: smolencev.smolencev@yandex.ru

Perevozkina, J. M. $\mid$ E-mail: per@bk.ru

Fedorishin, M. I. | E-mail: maskarad14@mail.ru 


\title{
Анализ предсказательных возможностей метакогнитивных стратегий в выраженности профессионального мышления военнослужащих
}

\author{
И. О. Смоленцев ${ }^{1}$ Ю. М. Перевозкина ${ }^{2}$, М. И. Федоришин ${ }^{2,3}$
}

\author{
${ }^{1}$ Саратовский военный ордена Жукова Краснознаменный институт войск национальной \\ гвардии Российской Федерации \\ ${ }^{2}$ Новосибирский государственный педагогический университет \\ ${ }^{3}$ Новосибирский военный ордена Жукова институт имени генерал армии И. К. Яковлева \\ войск национальной гвардии Российской Федерации
}

$\begin{array}{lr}\text { DOI: } 10.18255 / 1996-5648-2021-4-638-647 & \text { Научная статья } \\ \text { УДК 159.09 } & \text { Полный текст на русском языке }\end{array}$

В статье рассматривается профессиональное мышление применительно к условиям военной деятельности. Цель - выявление модели метакогнитивной компетентности курсантов, способствующей успешному становлению профессионального мышления в условиях воинской деятельности. Осуществлено построение двух регрессионных моделей посредством множественного пошагового регрессионного анализа с включением. В первой модели переменной откликом выступил надситуативный стиль мышления военнослужащих, определяемый по опроснику «Определение доминирующего уровня проблемности при решении служебно-профессиональных проблемных ситуаций». Во второй модели переменной откликом выступил тип профессионального мышления, определяемый на основе кейс-метода. В качестве переменных предикторов выступили метакогнитивные стратегии курсантов. Удалось установить, что обе регрессионные модели являются статистически значимыми, уровень вероятности ошибки менее 0,01\% и объясняют более 40 \% изменчивости переменных откликов. Все метакогнитивные стратегии (шесть переменных предикторов) в первой модели имеют статистически значимую связь с переменными откликами $(\mathrm{p} \leqslant 0,05)$. Прогностическое воздействие на доминирование у курсантов определенного типа профессионального мышления носит характер структурного взаимодействия. Такие метакогнитивные стратегии, как приобретение информации, концентрация, управление временем и уровень рефлексии, являются фрасилитаторами для формирования надситуативного уровня профессионального мышления курсантов. Тогда как метакогнитивные знания и метакогнитивная активность выступают ингибиторами.

Ключевые слова: профессиональное мышление; метакогнитивные стратегии; надситуативное мышление; структурность; взаимодетерминация; военнослужащие; курсанты

\section{ИНФОРМАЦИЯ ОБ АВТОРАХ}

\author{
Смоленцев, И. О., | E-mail: smolencev.smolencev@yandex.ru \\ Перевозкина, Ю. М. | E-mail: per@bk.ru \\ Федоришин, М. И. | E-mail: maskarad14@mail.ru
}

(с) Смоленцев И. О., Перевозкина Ю. М., Федоришин М. И., 2021

Статья открытого доступа под лицензией CC BY (https://creativecommons.org/licenses/by/4.0/) 
Смоленцев И. О., Перевозкина Ю. М., Федоришин М.И.

\section{Постановка проблемы исследования}

Сложные решения лежат в основе профессии военного. Более того, военные операции требуют ответов, которые имеют далеко идущие (иногда даже смертельные) последствия для самих военнослужащих и других вовлеченных сторон. Действительно, военнослужащие Росгвардии регулярно сталкиваются с решением служебно-боевых задач, связанных как с военно-профессиональной деятельностью, так и с взаимодействием с местным населением. Значимость метакогнитивных процессов для военнослужащих обусловлена быстрым технологическим развитием вооружения, приводящим к потенциально более серьезным последствиям действий ответственного лица и изменениям в его полномочиях по принятию решений. Это предполагает больше возможностей для собственной оценки ситуации и, следовательно, требует компетенций более высокого уровня.

В статье представлена разработка модели метакогнитивной компетентности, которая поможет концептуализировать спектр метакогнитивных способностей военнослужащих и прогнозировать возможность становления профессионального мышления, основанную на фрактических данных. Такая модель может использоваться не только для принятия решений при выполнении служебно-боевых задач военнослужащими, но и для содействия общему пониманию недостатков и пробелов в метакогнитивизме в военной психологии. Предлагается использовать такую модель в качестве основы для обучения, идентификации, планирования оценки и дизайна обучения курсантов.

В военной психологии представлены работы, которые направлены на изучение фракторов, влияющих на метакогнитивные стратегии. Так, I. Coffman с соавторами [1] показали, что посттравматическое стрессовое расстройство, депрессия и нарушение сна, которые относительно часто возникают среди военнослужащих, отрицательно коррелируют с количественными показателями метакогнитивной эффективности. Обучение, направленное на использование метакогнитивных стратегий военнослужащими, получившими черепно-мозговую травму, показало, что ежедневное использование метакогнитивной стратегии целеполагания позволяет им инициировать ряд других когнитивных стратегий в обеспечении повседневной жизни.

Опубликованы работы в которых демонстрируется наличие связи между командирскими навыками и метакогнитивными процессами воинского коллектива. Для выполнения общей миссии военнослужащие должны полагаться на общее понимание ситуации [2]. В процессе взаимодействия командира и личного состава необходим один и тот же интерпретирующий контекст. Именно общие ментальные модели могут представлять такой контекст. K. Kraiger \& L. H. Wenzel определили общие ментальные модели как «общие знания о команде и ее целях, а также общую информацию о командных ролях, моделях поведения и моделях взаимодействия» [3, с. 65]. 
Анализ предсказательных возможностей метакогнитивных стратегий...

Ментальные модели содержат инорормацию, связанную с постановкой задач, задействованными процедурами и стратегиями, проблемами, с которыми может иметь дело военнослужащий [4]. В исследовании J. Breslau с соавторами [5] представлены данные о связи метакогнитивных стратегий со сплоченностью военного коллектива. Данные, обсуждаемые L. Anderson с коллегами [6], показали, что сплоченность команды положительно связана с метакогнитивными ресурсами. Так, снижение социальной поддержки и уменьшение сплоченности между членами команды способствует уменьшению метакогнитивных ресурсов. Эти исследования базируются на широко известной теории сохранения ресурсов [7], которая описывает динамическую связь между стрессом и ресурсами.

В ряде работ по военной психологии было показано, что убеждения в самоэффективности повышают мотивацию и настойчивость для решения задач и проблем, ведущих к более высокому уровню эффрективности военнослужащих. B работе D. C. Chu с коллегами [8] продемонстрировано, что курсанты мужского пола по сравнению с представительницами женского пола отличались большей самоэффрективностью, самокоррекцией и самооценкой. Исследователи установили, что курсанты мужского пола более решительны и эффрективны в решении профессиональных задач, связанных с операциями ареста и применения полицейского оружия, в сравнении с их коллегами-женщинами. Более того, курсанты-мужчины достоверно более уверены в своих физических и умственных способностях для службы в полиции.

Метакогнитивные познания и переживания часто используются обучающимися в качестве эвристических сигналов, которые фрормируют основу их суждений об обучении [9]. Например, курсанты могут принять решение, основываясь на скорости, с которой этот план пришел в голову. Однако такое мышление не обязательно означает, что ответ курсанта правильный. Скорее, основанные на понимании сигналы, сорормированные причинным рассуждением, в большей степени предсказывают правильные ответы. В исследовании Р. Moonyoung [10] представлены критерии оценки проявления метакогнитивных стратегий при решении военно-профессиональных задач.

Анализируемые работы наглядно демонстрируют значимость метакогнитивных стратегий в становлении профессионального мышления военнослужащих, которое рассматривается как один из видов мышления, приобретающий ряд специорических черт, обусловленных особенностями военно-профессиональной деятельности. Основываясь на системном подходе, M. М. Кашапов [11] приходит к выводу, что психологическое содержание профессионального мышления заключается в структурно-уровневой самоорганизации процесса поиска, выявления и решения проблемности; актуализации профессионально ориентированных компонентов мышления, обеспечивающих реализацию профессиональной активности в соот- 
Смоленцев И. О., Перевозкина Ю. М., Федоришин М.И.

ветствии с содержанием и требованиями процесса профессиональной деятельности. Автор определяет профессиональное мышление как фрорму высшего познавательного процесса поиска, обнаружения и разрешения проблемности посредством выявления внешне не заданных, имплицитных свойств познаваемой и преобразуемой действительности. Следовательно, в обобщенном виде профессиональное мышление курсантов является видом мышления, позволяющим военнослужащему познавать сущность служебно-боевой задачи (проблемы); целенаправленно организовывать свои военно-профессиональные действия; самосовершенствовать свои интеллектуальные и личностные качества.

Таким образом, актуальным является выявление модели метакогнитивной компетентности курсантов, способствующей успешному становлению профессионального мышления в условиях воинской деятельности, что и явилось целью исследования.

\section{Методология и методы исследования}

Для реализации цели исследования использовался эмпирический план, предполагающий несколько этапов. На первом этапе были разработаны 10 кейсов-задач. За каждую решенную задачу курсантам присваивался балл по следующей шкале: 1 балл - решение остается в рамках заданной ситуации (ситуативный тип), 3 балла - решение выходит за рамки заданной ситуации (надситуативный тип) и 2 балла решение является смешанным (смешанный тип). По итогам решения 10 кейсов курсанту присваивается общий балл простым суммированием, который демонстрирует уровень профессионального мышления: 10-19 баллов - ситуативный тип профрессионального мышления; 20-24 балла - смешанный тип профессионального мышления; 25-30 баллов - надситуативный тип профрессионального мышления.

На втором этапе каждый курсант заполнил три методики: «Методику самооценки метакогнитивных знаний и метакогнитивной активности» Ю. В. Скворцовой, М. М. Кашапова, «Методику диагностики уровня развития рефрлексивности» А. В. Карпова и В. В. Пономоревой для установления особенностей выраженности метакогнитивных стратегий курсантов в ходе выполнения мероприятий военно-профессиональной деятельности и «Определение доминирующего уровня проблемности при решении служебно-профрессиональных проблемных ситуаций» M. M. Кашапова, Ю. Н. Дубровина.

На третьем этапе осуществлялось построение регрессионных моделей метакогнитивной компетентности курсантов, способствующей успешному становлению профессионального мышления. В первой модели переменной откликом выступил надситуативный стиль мышления военнослужащих, во второй модели - тип профессионального мышления, определяемый на основе кейс-метода. В качестве переменных предикторов 
Анализ предсказательных возможностей метакогнитивных стратегий...

выступили метакогнитивные стратегии курсантов. Математическим критерием для построения регрессионных моделей явился множественный пошаговый регрессионный анализ с включением [12].

Исследование проводилось на базе федеральной государственной казенной военной образовательной организации высшего образования «Новосибирский военный ордена Жукова институт имени генерала армии И. К. Яковлева войск национальной гвардии Российской Федерации». Выборку исследования составили 108 курсантов в возрасте от 21 до 25 лет, обучающиеся на пятом курсе.

\section{Результаты исследования и их анализ}

По результатам исследования удалось установить, что обе регрессионные модели являются статистически значимыми, уровень вероятности ошибки менее $0,01 \%$ (табл. 1 ).

Таблица 1

Итоговые статистики в регрессионных моделях

\begin{tabular}{|c|c|c|}
\hline Итоговые статистики & $\begin{array}{c}\text { ЗП: надситуативный уро- } \\
\text { вень профессионально- } \\
\text { го мышления }\end{array}$ & $\begin{array}{c}\text { 3П: тип профессионально- } \\
\text { го мышления }\end{array}$ \\
\hline Множест. R & 0,409 & 0,398 \\
\hline Множест. R2 & 0,367 & 0,358 \\
\hline $\mathrm{F}(5,194)$ & 6,453 & 6,041 \\
\hline p & 0,000 & 0,000 \\
\hline Стд. ош. оценки & 1,844 & 2,484 \\
\hline
\end{tabular}

Более того, все метакогнитивные стратегии имеют статистически значимую связь с переменными откликами, которыми выступили надситуативный уровень профрессионального мышления и тип профрессионального мышления. Взаимосвязь в обеих моделях превышает 0,4, и метакогнитивные стратегии объясняют вместе изменчивость надситуативного уровня профессионального мышления и типа профрессионального мышления более чем на $40 \%$.

Анализируя итоги регрессии для зависимой переменной - надситуативный уровень профессионального мышления, отметим, что наибольший положительный вклад в изменчивость надситуативного уровня профрессионального мышления вносит приобретение информации $(0,59)$ и концентрация (0,32), наименьший положительный вклад вносит управление временем $(0,18)$ и уровень рефлексии $(0,15)$ (табл. 2$)$.

В то же время наибольший отрицательный вклад вносят метакогнитивные знания $(-0,54)$ и метакогнитивная активность $(-0,21)$. Окончательная регрессионная модель выглядит следующим образом:

$$
\text { НУПМ }=10,78+0,55 \Pi И-0,36 M 3+0,45 K+0,38 У B+0,18 У Р P-0,18 M A .
$$


Смоленцев И. О., Перевозкина Ю. М., Федоришин М.И.

Таблица 2

\section{Итоги регрессии для зависимой переменной «надситуативный уровень профессионального мышления»}

\begin{tabular}{|l|c|c|c|c|c|c|}
\hline \multicolumn{1}{|c|}{ Предикторы } & БЕТА & Ст. ош. - БЕТА & В & Ст. ош. - В & t(193) & $\mathrm{p}$ \\
\hline Свободный член & & 0,14 & 0,55 & 0,13 & 4,31 & 0,000 \\
\hline $\begin{array}{l}\text { Приобретение } \\
\text { информации }\end{array}$ & 0,59 & 0,14 & $-0,36$ & 0,09 & $-3,96$ & 0,000 \\
\hline $\begin{array}{l}\text { Метакогнитив- } \\
\text { ные знания }\end{array}$ & $-0,54$ & 0,10 & 0,45 & 0,14 & 3,18 & 0,002 \\
\hline Концентрация & 0,32 & 0,07 & 0,30 & 0,12 & 2,49 & 0,013 \\
\hline $\begin{array}{l}\text { Управление } \\
\text { временем }\end{array}$ & 0,18 & 0,07 & 0,18 & 0,08 & 2,17 & 0,031 \\
\hline $\begin{array}{l}\text { Уровень разви- } \\
\text { тия рефрлексии }\end{array}$ & 0,15 & 0,10 & $-0,18$ & 0,09 & $-2,07$ & 0,040 \\
\hline $\begin{array}{l}\text { Метакогнитивная } \\
\text { активность }\end{array}$ & $-0,21$ & & & & 1,04 & 0,37 \\
\hline
\end{tabular}

Полученная формула демонстрирует, что при высокой развитости таких метакогнитивных стратегий, как приобретение информации и концентрация, курсанты способны выйти за пределы заданной военно-профессиональной ситуации. При этом они осуществляют постановку познавательных задач, касающихся процесса преобразования данной ситуации, ориентируясь на смыслообразующее направление и содержание служебно-боевой деятельности. Необходимо отметить, что именно способность управлять собственным вниманием, концентрироваться на выполнении служебно-боевых задач и приобретение военно-профессиональных знаний, а также их сохранение в большей степени способствует развитию у курсантов надситуативного уровня профессионального мышления. Вместе с тем высокая представленность в структуре личности метакогнитивных знаний и метакогнитивной активности, способствующих оценке своих знаний и управлению своим интеллектуальным поведением, свидетельствует о фиксации курсантов на ситуативном уровне решения заданной ситуации. Подобные результаты обнаружены ранее одним из авторов настоящей работы и заключаются в том, что высокая представленность в структуре личности курсантов саморегуляции оказывает отрицательное влияние на формирование метакогнитивных стратегий [13].

Внимательное рассмотрение итогов множественной регрессии демонстрирует подобный результат (табл. 3). Так, наибольший положительный вклад в становление типа профессионального мышления у курсантов по-прежнему вносят приобретение информации $(0,42)$ и концентрация $(0,2)$, к которым добавляется выбор главных идей $(0,34)$. Уровень развития рефр- 
Анализ предсказательных возможностей метакогнитивных стратегий...

лексии в обеих моделях имеет незначительный, но все же положительный вклад (0,13).

Таблица 3

Итоги регрессии для зависимой переменной «тип профессионального мышления»

\begin{tabular}{|l|c|c|c|c|c|c|}
\hline \multicolumn{1}{|c|}{ Предикторы } & БЕТА & Ст. ош.-БЕТА & В & Ст. ош. - В & †(193) & P \\
\hline Свободный член & & 0,13 & 0,53 & 0,17 & 3,16 & 0,002 \\
\hline $\begin{array}{l}\text { Приобретение } \\
\text { информации }\end{array}$ & 0,42 & 0,15 & $-0,42$ & 0,13 & $-3,17$ & 0,002 \\
\hline $\begin{array}{l}\text { Метакогнитивные } \\
\text { знания }\end{array}$ & $-0,46$ & 0,12 & 0,44 & 0,15 & 2,96 & 0,003 \\
\hline $\begin{array}{l}\text { Выбор главных } \\
\text { идей }\end{array}$ & 0,34 & 0,07 & 0,21 & 0,11 & 1,90 & 0,051 \\
\hline $\begin{array}{l}\text { Уровень разви- } \\
\text { тия ресрлексии }\end{array}$ & 0,13 & 0,10 & 0,38 & 0,19 & 1,96 & 0,052 \\
\hline Концентрация & 0,20 & 0,11 & $-0,20$ & 0,13 & $-1,54$ & 0,125 \\
\hline $\begin{array}{l}\text { Метакогнитивная } \\
\text { активность }\end{array}$ & $-0,17$ & & & & 15,59 & 0,000 \\
\hline
\end{tabular}

Наибольший отрицательный вклад вносит метакогнитивные знания $(-0,46)$, тогда как метакогнитивная активность имеет статистически не значимый отрицательный вклад и не может рассматриваться в анализируемой модели. Следовательно, окончательная регрессионная модель выглядит следующим образом:

$$
\text { ТПМ=22,61 + 0,53ПИ -0,42M3 + 0,44ВГИ +0,38K +0,21УРР. }
$$

Способность управлять собственным вниманием, концентрация на выполнении служебно-боевых задач и определение инфрормации, являющейся важной, а не второстепенной для дальнейшего изучения сложившейся ситуации, в большей степени способствует развитию у курсантов надситуативного уровня профессионального мышления. Это характеризует их как способных к поиску, обнаружению и разрешению проблемности в военно-профессиональной деятельности посредством выявления внешне не заданных, имплицитных свойств познаваемой и преобразуемой действительности. С другой стороны, высокая представленность в структуре личности метакогнитивных знаний, связанных со знанием своих индивидуальных когнитивных способностей и их оценкой свидетельствует о фиксации курсантов на ситуативном уровне решения задач. При развитости таких метакогнитивных стратегий, как приобретение иноромации и выбор главных идей в ходе поиска решения проблемной служебно-боевой задачи, открываются новые, ранее неизвестные военнослужащему, способы решения, что свидетельствует о надситуативном уровне профес- 
Смоленцев И. О., Перевозкина Ю. М., Федоришин М.И.

сионального мышления курсантов. В случае выраженности метакогнитивных знаний и метакогнитивной активности в процессе решения проблемной ситуации, военнослужащие будут в основном реконструировать ранее изученные способы выполнения поставленных задач, что, в свою очередь, связано с ситуативным уровнем профессионального мышления.

\section{Выводы}

1. Разработка модели метакогнитивной компетентности в становлении профессионального мышления курсантов продемонстрировала существование структурной детерминации профессионального мышления курсантов метакогнитивными качествами личности. Это означает, что метакогнитивные стратегии, организуясь в структурные образования, обусловливают совместную изменчивость типа профессионального мышления. Следовательно, в исследовательском плане открываются возможности, способствующие выходу за пределы анализа отдельной детерминации метакогнитивных стратегий выраженности профессионального мышления военнослужащих.

2. Принципиальным в плане решения исследовательских задач выступает то, как именно сорганизованы друг с другом метакогнитивные стратегии в структуре личности курсантов. Главным средством осуществления и регуляции профессионального мышления выступают такие метакогнитивные стратегии, как приобретение информации, выбор главных идей и концентрация. Эти стратегии, в свою очередь, являются интегративными механизмами, порождающими синергетические эффеекты. С другой стороны, такие стратегии, как метакогнитивные знания и метакогнитивная активность, вносят дезинтегрирующее влияние на становление надситуативного уровня профессионального мышления военнослужащего.

3. Концентрация внимания, управление временем и уровень рефрлексии являются фрасилитаторами для формирования надситуативного уровня профессионального мышления курсантов. Тогда как метакогнитивные знания и метакогнитивная активность выступают ингибиторами.

Представленные выводы вносят существенный вклад в метакогнитивную регуляцию профессионального мышления курсантов, а также являются методологической базой для изучения метакогнитивных процессов военно-профессиональной деятельности субъекта.

\section{Ссылки}

1. Computerized cognitive testing norms in active-duty military personnel: Potential for contamination by psychologically unhealthy individuals / I. Coffman [et al.] // Applied Neuropsychology: Adult, 2018. № 25 (6). P. 497-503.

2. Cohen S. G. and Mankin D. Collaboration in virtual organizations // Trends in organizational behavior / Edited by: C. L. Cooper and D. M. Rousseau. 1999. N 6. P. $105-120$. 
3. Kraiger K., \& Wenzel L. H. Conceptual Development and Empirical Evaluation of Measures of Shared Mental Models as Indicators of Team Effectiveness // Team Performance Assessment and Measurement Mahwah, NJ: Lawrence Erlbaum Associates. P. 63-84.

4. The influence of shared mental models on team process and performance / J. E. Mathieu [et. al.] // Journal of Applied Psychology. 2000. N 85 (2). P. 273-283.

5. Breslau J., Setodji M. J., Vaughan C. A. Is cohesion within military units associated with post-deployment behavioral and mental health outcomes? // Journal of Affective Disorders. 2016. N 198. P. 102-107.

6. Prospective associations of perceived unit cohesion with postdeployment mental health outcomes / L. Anderson, L. Campbell-Sills, R. J. Ursano [et al.] // Depression and Anxiety. 2019. N 36 (6). P. 511-521.

7. Conservation of resources in the organizational context: The reality of resources and their consequences / S. E Hobfoll [et al.] // Annual Review of Organizational Psychology and Organizational Behavior. 2018. N 5 (1). P. 103-128.

8. Chu D. C., Cretacci M. A. Comparison of Chinese male and female police cadets' perceived occupational self-efficacy // Policing and Society. 2020. N 30 (9). P. 1013-1026.

9. Zohar A., BarzilaiS. A review of research on metacognition in science education: current and future directions // Stud Sci Educ. 2013. N 49 (2). P. 121-169.

10. Moonyoung P. Investigating Target Tasks, Task Phases, and Indigenous Criteria for Military Aviation English Assessment // Language Assessment Quarterly. 2020. N 17 (4). P. 337-361.

11. Кашапов M. M. Рефлексивные закономерности и механизмы творческого педагогического мышления // Ярославский психологический вестник. М.; Ярославль: Российское психологическое общество, 2004. Вып. 12. С. 52-59.

12. Перевозкина Ю. М., Перевозкин С. Б. Основы математической статистики в психолого-педагогических исследованиях. Новосибирск: НГПУ, 2014. Ч. 2. 242 с.

13. Федоришин М. И. Взаимосвязь саморегуляции и индивидуализации в процессе обучения у курсантов ВООВО // Ярославский психологический вестник. М.; Ярославль: Российское психологическое общество, 2018. Вып. 2. С. 86-90. 